\title{
Physical Capacity of Occupationally Active Population and Capability to Perform Physical Work
}

\author{
Joanna Bugajska \\ Central Institute for Labour Protection - National Research Institute (CIOP-PIB), Poland \\ Teresa Makowiec-Dąbrowska \\ Alicja Bortkiewicz \\ Elžbieta Gadzicka \\ Nofer Institute of Occupational Medicine, Poland \\ Anna Marszałek \\ Central Institute for Labour Protection - National Research Institute (CIOP-PIB), Poland \\ Zbigniew Lewandowski \\ Medical University of Warsaw, Warszawa, Poland
}

\section{Maria Konarska}

Central Institute for Labour Protection - National Research Institute (CIOP-PIB), Poland

The aim of this study was to determine what proportion of occupationally active Poles have working capacity that enables them to tolerate hard and very hard physical work. For this purpose physical capacity of 1188 occupationally active subjects (524 women and 664 men), aged 18-64 years was examined. Their maximal oxygen consumption $\left(\mathrm{V}_{\text {O2max }}\right)$ was determined indirectly on the basis of their heart rate during an incremental exercise test on a bicycle ergometer. It was found that hard occupational physical work was an excessive load for almost 40\% of men and women. This paper discusses how this load should be decreased with planned, appropriately long rest breaks. The percentage of persons for whom their hard physical work becomes an excessive load increases with age to such a degree that a new assessment of individual capability for such work is recommended for persons over 40 years old.

$$
\text { physical capacity maximal oxygen consumption }\left(V_{\mathrm{O} 2 \max }\right) \text { work requirements }
$$

\section{INTRODUCTION}

Physical work is a risk factor for early loss of the ability to work, primarily due to musculoskeletal disorders and cardiovascular diseases, especially if this work is done by persons with low physical capacity $[1,2]$. Frequently employees, even if not fully aware of the health consequences of

This study was part of the PCZ 21-21 project "Occupational activity of employees in the context of an ageing society" commissioned by the Ministry of Labour and Social Policy and the State Committee for Scientific Research of Poland. This project was co-ordinated by the Central Institute for Labour Protection - National Research Institute.

Correspondence and requests for offprints should be sent to Joanna Bugajska, CIOP-PIB, ul. Czerniakowska 16, 00-701 Warszawa, Poland. E-mail: <jobug@ ciop.pl>. 
hard work, look for other jobs because of daily discomfort and fatigue.

Hard physical effort is usually related to manual materials handling (handling heavy tools or heavy packages with various goods), but also to a high tempo of activity (walking or manual work with a load, e.g., during packing). Physical work is hard not only at workstations in mining, construction, fishery, agriculture, roadworks and other earthworks, and during rescue operations, but also in transportation, e.g., in warehouses where manual trolleys are still used, in supermarkets (filling shelves), in health care (nursing), in packing and in industrial cleaning.

According to current Polish classification, men's physical work is hard when their energy expenditure during an 8-h shift is $6300-8400 \mathrm{~kJ}$, whereas women's work is hard when it is 4200 $5000 \mathrm{~kJ}$. Work is very hard when the energy expenditure during an 8-h shift exceeds $8400 \mathrm{~kJ}$ for men and $5000 \mathrm{~kJ}$ for women.

The detrimental effect of hard physical work for health depends on the level of workers' physical capacity. This capacity depends on the efficiency of the mechanisms of oxygen supply, i.e., the level of aerobic capacity, which is the amount of oxygen a person can consume during maximal effort that involves large groups of muscles (maximal oxygen uptake, $V_{\mathrm{O} 2 \max }$ ). The higher the $V_{\mathrm{O} 2 \max }$, the lower the relative workload, i.e., the relation between oxygen consumption during work and individual maximal oxygen uptake $\left(\% V_{\mathrm{O} 2 \max }\right)$. Relative load correlates well with many indicators of the intensity of various physiological processes that take place during exercise, i.e., the physiological cost of work, and with a subjective assessment of workload [3].

Experiments and observations conducted at workstations showed that for daily occupational work to be well tolerated, the load should not exceed $30-40 \%$ of $V_{\text {O2max }}[4,5,6,7,8,9$, 10, 11]. The upper limit of load during daily occupational work with scheduled rest breaks is $50 \% V_{\mathrm{O} 2 \max }$. Åstrand's experimental studies showed it was possible to work with such a load [12]. It is suggested that work with such a load should not be done continuously for more than one hour [7, 13]. Work whose intensity requires over $30 \% V_{\mathrm{O} 2 \max }$, and periodical effort over $50 \%$ $V_{\text {O2max }}$ for over $60 \mathrm{~min}$ in one day, is considered an excessive load [14].

By using recommendations on acceptable load and the current Polish classification of the intensity of workload, it is possible to calculate that hard physical work will not be an excessive load for men whose $V_{\mathrm{O} 2 \max }$ is $2.8-3.63 \mathrm{~L} / \mathrm{min}$, and for women whose $V_{\mathrm{O} 2 \max }$ is $2.0-2.33 \mathrm{~L} / \mathrm{min}$. Persons with that level of $V_{\mathrm{O} 2 \max }$ will use up to $30 \% V_{\mathrm{O} 2 \max }$ during hard physical work. If appropriate rest breaks are planned into hard physical work, this kind of work can be done by persons with lower $V_{\mathrm{O} 2 \max }(1.68-2.18 \mathrm{~L} / \mathrm{min}$ for men and 1.2-1.4 L/min for women), because rest breaks make workload of up to $50 \% V_{\mathrm{O} 2 \max }$ acceptable. Acceptable load during very hard physical work without rest breaks is tolerated only by men whose $V_{\mathrm{O} 2 \max }$ is greater than $3.63 \mathrm{~L} / \mathrm{min}$, and if there are rest breaks, by those with $V_{\mathrm{O} 2 \max }$ greater than $2.18 \mathrm{~L} / \mathrm{min}$. For women doing very hard work without rest breaks $V_{\mathrm{O} 2 \max }$ should exceed $2.33 \mathrm{~L} / \mathrm{min}$, and if there are rest breaks, it should exceed $1.4 \mathrm{~L} / \mathrm{min}$.

As every employee may in some circumstances have to do hard work, it is necessary to consider for what part of the population of employees this will not be an excessive load. The answer to this problem is also important for workers currently doing hard physical work. Thus, the main aim of this study is to establish what percentage of occupationally active men and women in Poland have physical capacity $\left(V_{\mathrm{O} 2 \max }\right)$ that makes it possible for them to do hard and very hard physical work that is not an excessive load on the body.

\section{MATERIALS AND METHODS}

\subsection{Subjects}

In total, 1188 occupationally active persons (664 men and 524 women) took part in the study. Table 1 illustrates their age structure.

The subjects were recruited from patients of occupational medicine physicians who were invited to co-operate. Their task was to recruit 
TABLE 1. Participants by Age and Gender

\begin{tabular}{lcccccc}
\hline & \multicolumn{7}{c}{ Age (years) } \\
\cline { 2 - 8 } Participants (\%) & $\mathbf{1 8 - 2 4}$ & $\mathbf{2 5 - 3 0}$ & $\mathbf{3 1 - 4 0}$ & $\mathbf{4 1 - 5 0}$ & $\mathbf{5 1 - 6 0}$ & $\geq \mathbf{6 1}$ \\
\hline Women & 2.9 & 10.7 & 19.3 & 38.7 & 26.5 & 1.9 \\
Men & 3.0 & 11.9 & 27.4 & 33.7 & 20.2 & 3.8 \\
\hline
\end{tabular}

subjects on the basis of a medical examination and an electrocardiogram (ECG) at rest. The procedure and the methodology of this study had been approved by the Ethics Committee at the Nofer Institute of Occupational Medicine in Łódź, Poland, and written informed consent was obtained from each subject.

After a verification of the intensity of the subjects' occupational workload on the basis of their reports on the type and duration of their occupational tasks, it was found that $31.3 \%$ of women did mental work, $35.1 \%$ light physical work, $27.3 \%$ moderate physical work and 5.3\% hard physical work; $18.4 \%$ of the male subjects did mental work, whereas 38.4, 24.7 and $14.5 \%$ did light, moderate and hard physical work, respectively.

\subsection{Procedure}

The subjects' physical capacity was determined indirectly by estimating $V_{\mathrm{O} 2 \max }$ and the linear relationship between heart rate and oxygen consumption (the amount of exercise) during an incremental submaximal exercise test on a bicycle ergometer with an initial load of $25 \mathrm{~W}$ (or $50 \mathrm{~W}$ for men under the age of 35 years), increased by $25 \mathrm{~W}$ every $3 \mathrm{~min}$. These tests were conducted until submaximal heart rate was reached $(80-85 \%$ of maximal heart rate calculated according to the formula $H R_{\max }=220$ - age) or they were stopped when there were clinical criteria indicating the end of exercise. On the basis of heart rate in the last minute of at least three loads, the subject's exercise intensity was extrapolated to the effort during which maximal heart rate would be reached. The aerobic capacity was adequate for hard physical work if $V_{\mathrm{O} 2 \max }$ was over $2.0 \mathrm{~L} / \mathrm{min}$ in women and over $2.8 \mathrm{~L} / \mathrm{min}$ in men. Persons with that level of $V_{\mathrm{O} 2 \max }$ will not involve more than $30 \%$ of their $V_{\mathrm{O} 2 \max }$ when doing physical work corresponding to the lower limit of hard work (oxygen consumption of over 0.6 for women and over $0.84 \mathrm{~L} / \mathrm{min}$ for men). The capacity for very hard physical work, during which oxygen consumption is over $0.7 \mathrm{~L} / \mathrm{min}$ for women and over $1.09 \mathrm{~L} / \mathrm{min}$ for men, was assessed in the same way: it was assumed that the level of $V_{\mathrm{O} 2 \max }$ should be over 2.33 for women and over $3.63 \mathrm{~L} / \mathrm{min}$ for men.

The subjects' basic anthropometric indicators, body mass and height, were measured, too.

\subsection{Statistics}

Statistical analysis was done with SAS 9.1.3. Analysis of variance was used for multiple comparisons in groups that differed in age and the type of work. Pearson's coefficient of correlation was calculated to assess the interdependence between the two characteristics. The level of statistical significance was set at $p<.05$.

\section{RESULTS}

\section{1. $V_{\text {O2max }}$ in Groups Identified According to Age and the Type of Physical Work}

The oldest age groups of both men and women had the lowest values of total $V_{\mathrm{O} 2 \max }$ and $V_{\mathrm{O} 2 \max }$ corrected by body weight. The highest level of $V_{\mathrm{O} 2 \max }$ in women was found in the youngest ones (18-24 and 25-30 years old) and corrected by body weight, 18-24 years old. For men, the highest level of $V_{\mathrm{O} 2 \max }$, both absolute and relative, was present not in the youngest, but in the slightly older age group, 25-30 years old (Table 2). There was $\sim 30 \%$ difference between the highest and lowest values of $V_{\mathrm{O} 2 \max }$ in both men and women.

Groups identified according to the type of work and the intensity of the workload did not 
TABLE 2. Total Maximal Oxygen Uptake $\left(V_{02 \max }\right)$ and $V_{\text {O2max }}$ Corrected by Body Weight in Women and Men by Age

\begin{tabular}{|c|c|c|c|c|c|c|}
\hline \multirow[b]{2}{*}{ Age (years) } & \multirow[b]{2}{*}{$N$} & \multicolumn{2}{|c|}{ Women $(M \pm S D)$} & \multirow[b]{2}{*}{$N$} & \multicolumn{2}{|c|}{ Men $(M \pm S D)$} \\
\hline & & $\begin{array}{c}\text { Total } V_{\text {O2max }} \\
(\mathrm{L} / \mathrm{min})\end{array}$ & $\begin{array}{l}\text { Corrected } V_{02 \max } \\
\left(\mathrm{ml} \cdot \mathrm{kg}^{-1} \cdot \mathrm{min}^{-1}\right)\end{array}$ & & Total $V_{02 \max }(\mathrm{L} / \mathrm{min})$ & $\begin{array}{l}\text { Corrected } V_{02 \max } \\
\left(\mathrm{ml} \cdot \mathrm{kg}^{-1} \cdot \mathrm{min}^{-1}\right)\end{array}$ \\
\hline $18-24$ & 15 & $2.5 \pm 0.4$ & $44.1 \pm 10.6$ & 20 & $3.4 \pm 0.8$ & $42.8 \pm 9.8$ \\
\hline 25-30 & 56 & $2.5 \pm 0.6$ & $42.3 \pm 7.7$ & 79 & $3.5 \pm 0.9$ & $44.1 \pm 10.4$ \\
\hline $31-40$ & 101 & $2.2 \pm 0.5$ & $36.0 \pm 7.6$ & 182 & $3.5 \pm 0.9$ & $43.5 \pm 10.9$ \\
\hline $41-50$ & 202 & $2.2 \pm 0.7$ & $32.9 \pm 9.4$ & 222 & $3.2 \pm 0.9$ & $38.5 \pm 10.9$ \\
\hline $51-60$ & 138 & $1.9 \pm 0.6$ & $28.9 \pm 8.8$ & 134 & $2.7 \pm 0.9$ & $33.4 \pm 10.6$ \\
\hline$\geq 61$ & 10 & $1.7 \pm 0.4$ & $26.0 \pm 7.1$ & 25 & $2.4 \pm 0.7$ & $29.9 \pm 9.5$ \\
\hline
\end{tabular}

Notes. Corrected $V_{\mathrm{O} 2 \max }-V_{\mathrm{O} 2 \max }$ corrected by body weight, $r$-coefficient of correlation with age.

TABLE 3. Maximal Oxygen Uptake $\left(V_{02 \max }\right)$ in Women by Age, Type of Work and Intensity of Workload

\begin{tabular}{|c|c|c|c|c|c|c|c|c|}
\hline \multirow{3}{*}{$\begin{array}{l}\text { Type of Work } \\
\text { and Intensity } \\
\text { of Workload }\end{array}$} & \multicolumn{8}{|c|}{ Women } \\
\hline & \multirow[b]{2}{*}{$\mathbf{N}$} & Age (years) & $\begin{array}{l}\text { Total } V_{\text {O2max }} \\
\text { (L/min) }\end{array}$ & $\begin{array}{l}\text { Corrected } V_{02 \max } \\
\left(\mathrm{ml} \cdot \mathrm{kg}^{-1} \cdot \mathrm{min}^{-1}\right)\end{array}$ & \multicolumn{4}{|c|}{ Decrease With Age } \\
\hline & & \multicolumn{3}{|c|}{$M \pm S D$} & $\begin{array}{c}V_{\text {O2max }} \\
\text { (ml/year) }\end{array}$ & $r$ & $\begin{array}{l}\text { Corrected } V_{02 \max } \\
\left(\mathrm{ml} \cdot \mathrm{kg}^{-1} \cdot \mathrm{min}^{-1}\right)\end{array}$ & $r$ \\
\hline Mental & 164 & $43.8 \pm 10.1$ & $2.0 \pm 0.5$ & $32.6 \pm 9.6$ & 22 & -.427 & 0.51 & -.540 \\
\hline \multicolumn{9}{|l|}{ Physical } \\
\hline light & 184 & $43.1 \pm 9.7$ & $2.2 \pm 0.6$ & $34.9 \pm 9.9$ & 13 & -.206 & 0.41 & -.399 \\
\hline moderate & 143 & $45.3 \pm 10.4$ & $2.1 \pm 0.6$ & $32.9 \pm 9.6$ & 18 & -.300 & 0.38 & -.417 \\
\hline hard & 28 & $40.1 \pm 10.8$ & $2.3 \pm 0.7$ & $34.7 \pm 9.3$ & 30 & -.496 & 0.40 & -.466 \\
\hline
\end{tabular}

Notes. Corrected $V_{\mathrm{O} 2 \max }-V_{\mathrm{O} 2 \max }$ corrected by body weight, $r$ coefficient of correlation with age.

TABLE 4. Maximal Oxygen Uptake $\left(V_{\text {O2max }}\right)$ in Men by Age, Type of Work and Intensity of Workload

\begin{tabular}{|c|c|c|c|c|c|c|c|c|}
\hline \multirow{4}{*}{$\begin{array}{l}\text { Type of Work } \\
\text { and Intensity } \\
\text { of Workload }\end{array}$} & \multicolumn{8}{|c|}{ Men } \\
\hline & \multirow[b]{3}{*}{$\boldsymbol{N}$} & \multirow[b]{2}{*}{ Age (years) } & \multirow{2}{*}{$\begin{array}{l}V_{\text {O2max }} \\
(\mathrm{L} / \mathrm{min})\end{array}$} & \multirow{2}{*}{$\begin{array}{l}\text { Corrected } V_{02 \max } \\
\left(\mathrm{ml} \cdot \mathrm{kg}^{-1} \cdot \mathrm{min}^{-1}\right)\end{array}$} & \multicolumn{4}{|c|}{ Decrease With Age } \\
\hline & & & & & \multirow{2}{*}{$-\begin{array}{c}V_{\text {O2max }} \\
\text { (ml/year) }\end{array}$} & \multirow[b]{2}{*}{$r$} & \multirow{2}{*}{$\begin{array}{c}\text { Corrected } V_{02 \max } \\
\left(\mathrm{ml} \cdot \mathrm{kg}^{-1} \cdot \mathrm{min}^{-1}\right)\end{array}$} & \multirow[b]{2}{*}{$r$} \\
\hline & & & $M \pm S$ & & & & & \\
\hline Mental & 122 & $43.1 \pm 10.0$ & $2.9 \pm 0.7$ & $36.3 \pm 7.9$ & 14 & -.213 & 0.28 & -.359 \\
\hline \multicolumn{9}{|l|}{ Physical } \\
\hline light & 255 & $43.6 \pm 10.4$ & $3.3 \pm 1.0$ & $40.0 \pm 12.0$ & 33 & -.350 & 0.41 & -.351 \\
\hline moderate & 164 & $42.1 \pm 10.4$ & $3.2 \pm 1.0$ & $39.6 \pm 12.7$ & 31 & -.321 & 0.42 & -.342 \\
\hline hard & 96 & $41.8 \pm 10.1$ & $3.3 \pm 1.0$ & $40.0 \pm 11.2$ & 47 & -.478 & 0.55 & -.491 \\
\hline
\end{tabular}

Notes. Corrected $V_{\mathrm{O} 2 \max }-V_{\mathrm{O} 2 \max }$ corrected by body weight, $r$-coefficient of correlation with age.

differ in age. Only women doing hard physical work were significantly younger than those doing moderate work $(p=.017)$. Tables 3-4 illustrate the values of $V_{\mathrm{O} 2 \max }$ in groups with various workload. Both men and women who did mental work had the lowest level of $V_{\text {O2max }}$; women doing hard physical work and men doing light and hard physical work had the highest. The level of $V_{\mathrm{O} 2 \max }$ in women doing mental work was significantly lower than in women who did light and hard physical work $(p=.009$ and $p=.007$, respectively). The level of $V_{\mathrm{O} 2 \max }$ was lower in men doing mental work than in those doing physical work. Neither in men nor in women did the level of $V_{\text {O2max }}$ significantly differ depending on the intensity of physical workload.

There was negative correlation between the values of $V_{\mathrm{O} 2 \max }$ and age both in the whole 
sample and in the subsamples identified according to the type of work and the intensity of workload (Tables 3-4). The level of $V_{\mathrm{O} 2 \max }$ decreased in women by 0.38 and $0.51 \mathrm{ml} / \mathrm{kg}$ per year of age, whereas in men by 0.28 and $0.55 \mathrm{ml} / \mathrm{kg}$ per year of age. Both men and women doing hard physical work had the highest correlation coefficients.

\subsection{The Capacity for Hard or Very Hard Physical Work Depending on Age, the Type of Work and the Intensity of the Workload}

Tables 5-6 show the percentage of men and women for whom doing hard and very hard work would be an excessive load. The percentage of persons for whom hard occupational effort is excessive increases with age. Work of an intensity corresponding to the lower limit of hard work would not be an excessive load only for women aged 18-24 years; whereas work of an intensity equal to the upper limit of hard work (and the lower limit of very hard work) would be an excessive load for as many as $40 \%$ of them. Going over the limit of hard physical work is an excessive load for over $60 \%$ of women over 50; whereas going over the limit of very hard work would be an excessive load for over $80 \%$ of women of that age. An analysis of $V_{\mathrm{O} 2 \max }$ in men showed that in $20 \%$ of participants in the $25-30$ years age group and in $88 \%$ of subjects over the age of 60 years, physical capacity corresponded to the lower limit of hard work and their occupational work was an excessive load. Work of an intensity equivalent to the boundary between hard and very hard was an excessive load for a very high percentage of men: from almost $60 \%$ in the $31-40$-year-old group to $92 \%$ in the over-60 group.

TABLE 5. Women by Age (95\% Cl), for Whom Oxygen Consumption at the Level of 0.7 or $0.6 \mathrm{~L} / \mathrm{min}$ During Very Hard or Hard Physical Work Constitutes Over 30 or Over $50 \% V_{\text {O2max }}$

\begin{tabular}{|c|c|c|c|c|c|c|c|c|}
\hline \multirow{4}{*}{$\begin{array}{l}\text { Age } \\
\text { (years) }\end{array}$} & \multicolumn{8}{|c|}{ Women (\%) } \\
\hline & \multicolumn{4}{|c|}{$>30 \% V_{02 \max }$} & \multicolumn{4}{|c|}{$>50 \% V_{02 \max }$} \\
\hline & \multicolumn{2}{|c|}{ Very Hard Work } & \multicolumn{2}{|c|}{ Hard Work } & \multicolumn{2}{|c|}{ Very Hard Work } & \multicolumn{2}{|c|}{ Hard Work } \\
\hline & $M$ & Range & $M$ & Range & $M$ & Range & $M$ & Range \\
\hline $18-24$ & 40.0 & $16.3-67.7$ & 0 & $0-21.8$ & 0 & $0-21.8$ & 0 & $0-21.8$ \\
\hline $25-30$ & 44.6 & $31.3-58.5$ & 10.7 & $4.0-21.9$ & 0 & $0-6.4$ & 0 & $0-6.4$ \\
\hline $31-40$ & 67.3 & $57.3-76.3$ & 27.7 & 19.3-37.5 & 2.9 & $0.6-8.4$ & 0 & $0-3.6$ \\
\hline $41-50$ & 67.8 & $60.9-74.2$ & 45.5 & $38.5-52.7$ & 7.4 & $4.0-12.0$ & 2.5 & $0.8-5.7$ \\
\hline $51-60$ & 81.2 & 73.6-87.3 & 65.2 & $56.7-73.1$ & 14.5 & $9.1-21.5$ & 5.2 & $2.1-10.2$ \\
\hline$\geqq 61$ & 90.0 & $55.5-99.8$ & 60.0 & 26.2-87.8 & 30.0 & $6.7-65.3$ & 10.0 & $0.3-44.5$ \\
\hline
\end{tabular}

Notes. $\mathrm{Cl}-$ confidence interval.

TABLE 6. Men by Age $(95 \% \mathrm{Cl})$, for Whom Oxygen Consumption at the Level of 1.09 or $0.84 \mathrm{~L} / \mathrm{min}$ During Very Hard or Hard Physical Work Constitutes Over 30 or Over $50 \% V_{O 2 \max }$

\begin{tabular}{|c|c|c|c|c|c|c|c|c|}
\hline \multirow{4}{*}{$\begin{array}{l}\text { Age } \\
\text { (years) }\end{array}$} & \multicolumn{8}{|c|}{ Men (\%) } \\
\hline & \multicolumn{4}{|c|}{$>30 \% V_{02 \max }$} & \multicolumn{4}{|c|}{$>50 \% V_{02 \max }$} \\
\hline & \multicolumn{2}{|c|}{ Very Hard Work } & \multicolumn{2}{|c|}{ Hard Work } & \multicolumn{2}{|c|}{ Very Hard Work } & \multicolumn{2}{|c|}{ Hard Work } \\
\hline & $M$ & Range & $M$ & Range & $M$ & Range & $M$ & Range \\
\hline $18-24$ & 75.0 & 50.9-91.3 & 25.0 & $8.7-49.1$ & 0 & $0-17$ & 0 & $0-16.8$ \\
\hline $25-30$ & 64.6 & $52.3-75.0$ & 20.3 & $12.0-30.8$ & 1.3 & $0.03-6.9$ & 0 & $0-4.6$ \\
\hline $31-40$ & 56.6 & $49.1-63.9$ & 22.5 & $16.7-29.3$ & 1.7 & $0.3-4.7$ & 0.5 & $0.01-3.0$ \\
\hline $41-50$ & 74.8 & $68.5-80.4$ & 38.7 & $32.2-45.5$ & 10.8 & $7.1-15.7$ & 1.4 & $0.3-3.9$ \\
\hline $51-60$ & 88.8 & $82.2-93.6$ & 62.7 & $53.9-70.9$ & 25.4 & 18.3-33.6 & 6.7 & $3.1-12.4$ \\
\hline$\geq 61$ & 92.0 & $74.0-99.0$ & 88.0 & $68.8-97.5$ & 32.0 & $15.0-53.5$ & 12.0 & $2.6-31.2$ \\
\hline
\end{tabular}

Notes. $\mathrm{Cl}$-confidence interval. 
An adequate number of rest breaks at work would increase the capacity for hard and very hard physical work, when the acceptable load is $50 \% V_{\mathrm{O} 2 \max }$. In those circumstances all women under the age of 40 years would be able to do work of an intensity equivalent to the lower limit of hard work, and all women under 30 years of age would be able to do work of an intensity equal to the lower limit of very hard work. Work of an intensity corresponding to the lower and upper limit of hard work would be an excessive load only in 10 and $30 \%$ of women over 60 years old, respectively. A rational organization of work would make it possible for all men under 40 years to do hard physical work in the lower limit of intensity, and for all men under the age of 24 years in the upper range of intensity. Hard work would be an excessive load only for $12-32 \%$ of men over 60 years old.
Similar principles were used to estimate the percentage of men and women doing mental work or light, moderate or hard physical work for whom hard and very hard work would be an excessive load (Tables 7-8). It turned out that hard physical work was an excessive load for almost $40 \%$ of men and women; their $V_{\mathrm{O} 2 \max }$ was lower than that required for persons doing work of an intensity equal to the lower limit of hard work. Work of an intensity corresponding to the upper limit of hard work was an excessive load for over $60 \%$ men and women.

Hard physical work can be an excessive load for a small percentage of men and women only if there are adequately long rest breaks. Persons who did light physical work every day had the greatest capacity for hard physical work, but even so for $\sim 34 \%$ of men and $\sim 38 \%$ of women exceeding its lower limit of intensity would be an excessive load.

TABLE 7. Women by Type of Work and Intensity of Workload $(95 \% \mathrm{Cl})$, for Whom Oxygen Consumption at the Level of 0.7 or $\mathbf{0 . 6} \mathrm{L} / \mathrm{min}$ During Very Hard or Hard Physical Work Constitutes Over 30 or Over $50 \% V_{02 \max }$

\begin{tabular}{|c|c|c|c|c|c|c|c|c|}
\hline \multirow{4}{*}{$\begin{array}{l}\text { Type of Work } \\
\text { and Intensity } \\
\text { of Workload }\end{array}$} & \multicolumn{8}{|c|}{ Women (\%) } \\
\hline & \multicolumn{4}{|c|}{$>30 \% V_{02 \max }$} & \multicolumn{4}{|c|}{$>50 \% V_{02 \max }$} \\
\hline & \multicolumn{2}{|c|}{ Very Hard Work } & \multicolumn{2}{|c|}{ Hard Work } & \multicolumn{2}{|c|}{ Very Hard Work } & \multicolumn{2}{|c|}{ Hard Work } \\
\hline & $M$ & Range & $M$ & Range & $M$ & Range & $M$ & Range \\
\hline Mental & 78.1 & $71.4-84.7$ & 47.6 & $39.7-55.5$ & 10.4 & $6.2-16.1$ & 3.7 & $0.5-6.8$ \\
\hline \multicolumn{9}{|l|}{ Physical } \\
\hline light & 58.7 & $51.3-66.1$ & 37.5 & $30.5-44.9$ & 4.9 & $2.3-9.1$ & 2.7 & $0.1-5.3$ \\
\hline moderate & 71.6 & $63.8-79.4$ & 44.7 & $36.3-53.3$ & 9.2 & $5.0-15.3$ & 1.4 & $0-3.7$ \\
\hline hard & 64.3 & $44.8-83.8$ & 39.3 & $21.5-59.4$ & 3.6 & $0.1-18.4$ & 0 & $0-2.3$ \\
\hline
\end{tabular}

Notes. $\mathrm{Cl}-$ confidence interval.

TABLE 8. Men by Type of Work and Intensity of Workload (95\% Cl), for Whom Oxygen Consumption at the Level of $\mathbf{1 . 0 9}$ or $\mathbf{0 . 8 4} \mathrm{L} / \mathrm{min}$ During Very Hard or Hard Physical Work Constitutes Over 30 or Over $50 \% v_{02 \max }$

\begin{tabular}{|c|c|c|c|c|c|c|c|c|}
\hline \multirow{4}{*}{$\begin{array}{l}\text { Type of Work } \\
\text { and Intensity } \\
\text { of Workload }\end{array}$} & \multicolumn{8}{|c|}{ Men (\%) } \\
\hline & \multicolumn{4}{|c|}{$>30 \% V_{02 \max }$} & \multicolumn{4}{|c|}{$>50 \% V_{02 \max }$} \\
\hline & \multicolumn{2}{|c|}{ Very Hard Work } & \multicolumn{2}{|c|}{ Hard Work } & \multicolumn{2}{|c|}{ Very Hard Work } & \multicolumn{2}{|c|}{ Hard Work } \\
\hline & $M$ & Range & $M$ & Range & $M$ & Range & $M$ & Range \\
\hline Mental & 88.4 & 82.3-94.5 & 43.0 & $34.0-52.3$ & 12.4 & $7.1-19.6$ & 1.7 & $0-4.3$ \\
\hline \multicolumn{9}{|l|}{ Physical } \\
\hline light & 69.0 & $63.2-74.9$ & 34.0 & $29.1-41.1$ & 10.2 & $6.8-14.6$ & 2.4 & $0.3-4.4$ \\
\hline moderate & 69.5 & $62.2-76.9$ & 42.7 & $35-56.6$ & 10.4 & $6.2-16.1$ & 2.4 & $0-5.1$ \\
\hline hard & 64.2 & $54.0-74.4$ & 36.8 & $27.2-47.4$ & 12.6 & $6.7-21.0$ & 4.2 & $0-8.8$ \\
\hline
\end{tabular}

Notes. $\mathrm{Cl}$-confidence interval. 


\section{DISCUSSION}

$V_{\mathrm{O} 2 \max }$ is an indicator of the capacity of the cardiovascular and the respiratory systems, which makes it possible to perform longlasting, physical effort. In practice it is an indicator of physical capacity. Its level in the individual age groups of the female participants can be considered average if the obtained values of $V_{\mathrm{O} 2 \max }$ are evaluated according to Åstrand's classification of capacity [12], and good if Shvartz and Reinbold's classification [15, 16] is used. The assessment of the male subjects' level of capacity is more complex. In the age groups under 30 years the mean values of $V_{\mathrm{O} 2 \max }$ indicated an average level of capacity, and in the older ones a high level, according to Åstrand, and good according to Shvartz and Reinbold. The rate with which the level of $V_{\mathrm{O} 2 \max }$ decreases with age, $\sim 0.74 \%$ per year of life for the subjects, is close to that reported by de Zwart, Frings-Dresen and van Dijk [17] on the basis of the results of 20 cross-sectional studies.

When the level of physical capacity was assessed on the basis of the type of work and the intensity of the workload, it was found that it was good in men and women who did physical work, and average in men and women who did mental work (according to Åstrand [12] and Shvartz and Reinbold $[15,16])$.

The obtained data on the level of $V_{\mathrm{O} 2 \max }$ in the participants of this study provide a view on the capacity for hard physical work. It is relatively good in subjects under 40 years of age (worse in men than in women under 30). However, it later decreases to such a degree that only for $35 \%$ of persons $50-60$ years old work requiring oxygen consumption in the lower range of hard work would not constitute an excessive load (i.e., would be lower than $30 \% V_{\text {O2max }}$ ). The upper range of hard work is not an excessive load for a worryingly low percentage of men (only 25 and $35 \%$ ) in the youngest age groups, and for slightly more than half of the women of the same age. After the age of 40 years, hard work would not be an excessive load only for fewer than $30 \%$ of men and women. The fact that only such a small percentage of persons over the age of 40 years is really capable of hard physical work shows that the requirements for physical effort should be lowered as workers grow older, i.e., among persons with hard work, there should be fewer older people than among those with a low physical load. The World Health Organization has recommended this principle since the beginning of the 1990s [18]. However, it has not been fully respected; the results of an analysis of the working conditions in European Union member states show that the level of physical load is not different in young and older workers [19]. Neither did our study show any significant differences in age in groups doing work with different intensity of workload. The fact that women doing hard physical work turned out to be significantly younger than the others can result not from the fact that the load for older women decreases but rather from the fact that with such a load, they more frequently take advantage of the opportunity to take early retirement [20].

Several studies indicate there are relationships between physical capacity and the kind of occupational work, or the duration and intensity of physical effort related to that work. The correlation is positive, at least in young persons, which suggests a rather good job fit [21]. On the other hand, prospective studies show that doing hard physical work for many years means that workers' physical capacity decreases faster than that of persons doing light work [22, 23]. This is supposed to prove that doing such work is not related to the training effect. Our results also indicated a faster decrease in the level of $V_{\text {O2max }}$ in persons doing hard physical work. However, physical effort in occupational work has a significant influence on the level of $V_{\mathrm{O} 2 \max }$. Studies showed that a significant decrease in workload for even 6-9 months resulted in a decrease in $V_{\text {O2max }}$ of $20-30 \%$, i.e., $V_{\text {O2max }}$ decreased to a level characteristic for workers doing light physical or mental work [24]. In the present study both men and women who worked hard physically had a higher level of $V_{\mathrm{O} 2 \max }$ than those doing work that did not require physical effort. This was probably caused by natural selection, i.e., those whose capability for effort 
was too low to meet the requirements of work probably gave it up themselves. Spioch's research results in a study performed in metallurgists repairing iron blast furnaces suggest this interpretation [25]. Even though the metallurgists performed very hard physical work and were exposed to heat, their physical capacity assessed on the basis of $V_{\mathrm{O} 2 \max }$ was very high in all age groups; however, only $\sim 4 \%$ persons in the whole group were aged 56-60 years.

The level of $V_{\mathrm{O} 2 \max }$ of those of our subjects who did hard physical work was good. Even so, for almost $40 \%$ of both men and women hard physical work can be an excessive load greater than $30 \% V_{\text {O2max }}$. This can have detrimental consequences, the first signal of which is chronic fatigue [26].

Decreasing individual load for persons doing hard work should focus on a rational selection for such work and on good work organization. Hard work should be assigned on the basis of a determination of $V_{\mathrm{O} 2 \max }$ and on a selection of persons whose level of physical capacity is at least good. According to methodological guidelines on preventive tests of workers, an assessment of $V_{\mathrm{O} 2 \max }$ is recommended if physical work requires energy expenditure of over $6300 \mathrm{~kJ} / 8 \mathrm{~h}$ or $12.6 \mathrm{~kJ} / \mathrm{min}$ for men and over $4200 \mathrm{~kJ} / 8 \mathrm{~h}$ or over $8.4 \mathrm{~kJ} / \mathrm{min}$ for women. However, interviews with the subjects indicated that such tests were rarely part of preventive medical tests. The capacity for hard work can be increased through good work organization that involves appropriately long and frequent rest breaks. Our results have shown that if work of all those who work hard was organized well, it would be excessive (i.e., the workload would exceed $\left.50 \% V_{\text {O2max }}\right)$ for only a few percent of women and a dozen or so percent of men.

However, when determining what occupational workload is acceptable, it should be born in mind that the limit of 30 and $50 \% V_{\mathrm{O} 2 \max }$ applies to work that involves large groups of muscles (muscle activity of the limbs and the trunk). Oxygen consumption during maximal effort, the load of the cardiovascular system and the subjective feeling related to effort depend on the mass of the muscles involved [27, 28, 29]. Effort, which can be low when large groups of muscles are involved, can be very high when it involves small muscles. So, using $V_{\text {O2max }}$ determined during exercise that involved legs for all kinds of work can result in overestimating the real capacity for everyday occupational work. During work like manual materials handling, $V_{\mathrm{O} 2 \max }$ is much lower than that during exercise on a treadmill or a bicycle ergometer. That is why determining acceptable oxygen consumption during transportation work with $V_{\mathrm{O} 2 \max }$ obtained during that particular effort is recommended [30]. The differences between oxygen consumption acceptable for 8-h work that is calculated with total and specific $V_{\mathrm{O} \max }$ can be significant. Assuming that oxygen consumption during 8-h work without additional rest breaks should not exceed $30 \%$, and if there are breaks it should not exceed $50 \% V_{\mathrm{O} \max }$ specific for a given type of effort, then during transportation it should not exceed 24 and $41 \%$ of total $V_{\mathrm{O} 2 \max }$, respectively [31].

While not underestimating the role of physical capacity in work tolerance, especially tolerance of hard and very hard physical effort, introducing appropriate breaks at work should be widely recommended as this is the most significant factor that could make a decrease in a worker's load possible.

\section{CONCLUSIONS}

$V_{\mathrm{O} 2 \max }$ in men and women doing physical work is higher than in persons doing mental work. The percentage of persons for whom hard physical work would be an excessive load increases with age to such a degree that a new assessment of individual capability for such work is recommended for persons over 40 years old.

The level of physical capacity in industrial workers was insufficient for hard physical effort not to be an excessive workload; for $\sim 40 \%$ of men and women their hard physical work constituted a load that exceeded $30 \% V_{\mathrm{O} 2 \max }$. 


\section{REFERENCES}

1. Karpansalo M, Manninen P, Lakka TA, Kauhanen J, Rauramaa R, Salonen JT. Physical workload and risk of early retirement: prospective population-based study among middle-aged men. J Occup Environ Med. 2002;44(10):930-9.

2. Ilmarinen J. Work and cardiovascular health: viewpoint of occupational physiology. Ann Med. 1989;21(3):209-14.

3. Åstrand PO, Rodahl K. Textbook of work physiology. Physiological bases of exercise. New York, NY, USA: McGrawHill; 1986.

4. Michael ED Jr, Hutton KE, Horvath SM. Cardiorespiratory responses during prolonged exercise. J Appl Physiol. 1961; 16:997-1000.

5. Bink B. The physical working capacity in relation to working time and age. Ergonomics. 1962;5:25-8.

6. Lehman G. Praktische Arbeitsphysiologie [Practical occupational physiology]. 2nd ed. Stuttgart, Germany: Thieme; 1962.

7. Rodgers SH. Work physiology—fatigue and recovery. In: Salvendy G, editor. Handbook of human factors and ergonomics. New York, NY, USA: Wiley; 1997. p. 281-2.

8. Chaffin DB, Couto Hde A. Correlation of aerobic capacity of Brazilian workers and their physiologic work requirements. J Occup Med. 1986;28(7):509-13.

9. Saha PN, Datta SR, Banerjee PK, Narayane GG. An acceptable workload for Indian workers. Ergonomics. 1979; 22:1059-71.

10. Ilmarinen J. Job design for the aged with regard to decline in their maximal aerobic capacity: part I. Guidelines for the practitioner. Int J Ind Ergon. 1992;10:53-63.

11. Wu HC, Wang MJ. Relationship between maximum acceptable work time and physical workload. Ergonomics. 2002; 45(4):280-9.

12. Åstrand I. Aerobic work capacity in men and women with special reference to age. Acta Physiol Scand Suppl. 1960;49(169):1-92.
13. Rutenfranz J. Energy expenditure constrained by sex and age. Ergonomics. 1985; 28(1):115-8.

14. Kemper HC, van Aalst R, Leegwater A, Maas S, Knibbe J. The physical and physiological workload of refuse collectors. Ergonomics. 1990;33(12):1471-86.

15. Åstrand PO. Experimental studies on physical working capacity in relation to sex and age. Copenhagen, Denmark: Munksgaard; 1952.

16. Shvartz E, Reinbold RC. Aerobic fitness norm for males and females aged 6 to 75 years, a review. Aviat Space Environ Med. 1990;61(1):3-11.

17. de Zwart BCH, Frings-Dresen MHW, van Dijk FJ. Physical workload and the aging worker: a review of the literature. Int Arch Occup Environ Health. 1995;68:1-12.

18. World Health Organization (WHO). Aging and working capacity. Report of a WHO study group (WHO technical report series 835). Geneva, Switzerland: WHO; 1993.

19. Ilmarinen J. Physical requirements associated with the work of aging workers in the European Union. Exp Aging Res. 2002; 28(1):7-23.

20. Szubert Z, Sobala W. Some job factors associated with departure from working life before retirement age. Med Pr. 2006; 57(4):325-34. In Polish, with an abstract in English.

21. Tammelin $T$, Näyhä $S$, Rintamäki $H$, Zitting P. Occupational physical activity is related to physical fitness in young workers. Med Sci Sports Exerc. 2002; 34(1):158-65.

22. Nygård C-H, Kilbom Å, Wigaeus Hjelm E, Winkel J. Life-time occupational exposure to heavy work and individual physical capacity. Int J Ind Ergon. 1994;14(4):365-72.

23. Leino-Arjas $P$, Solovieva S, Riihimäki H, Kirjonen J, Telama R. Leisure time, physical activity and strenuousness of work as predictors of physical functioning: a 28-year follow up of a cohort of industrial employees. Occup Environ Med. 2004;61(12):1032-8.

24. Kozłowski S, Kirschner H, Kamiński A, Starnowski R. Relation of the predicted maximal oxygen consumption $\left(V_{\mathrm{O} 2 \max }\right)$ in 
humans to the age of workers in various professions. Pol Arch Med Wewn. 1969; 42(2):173-80. In Polish, with an abstract in English.

25. Spioch F. Effect of long-term work in hot microclimate on various physiological parameters in metallurgists. Med Pr. 1979; 30(6):393-401. In Polish, with an abstract in English.

26. Makowiec-Dąbrowska T, Koszada-Włodarczyk W. The CIS20R questionnaire and its suitability for prolonged fatigue studies. Med Pr. 2006;57(4):335-45. In Polish, with an abstract in English.

27. Sargeant AJ, Davies CTM. Perceived exertion during rhythmic exercise involving different muscle masses. J Hum Ergol. 1973;2(1):3-11.

28. Lewis SF, Taylor WF, Graham RM, Pettinger WA, Schutte JE, Blomqvist CG.
Cardiovascular responses to exercise as functions of absolute and relative work load. J Appl Physiol. 1983;54(5):1314-23.

29. Louhevaara V, Teräslinna $P$, Piirilä $P$, Salmio S, Ilmarinen J. Physiological responses during and after intermittent sorting of postal parcels. Ergonomics. 1988;31(8):1165-75.

30. Khalil TM, Genaidy AM, Asfour SS, Vinciguerra T. Physiological limits in lifting. Am Ind Hyg Assoc J. 1985; 46(4):220-4.

31. Rutenfranz J, Ilmarinen J, Klimmer F, Kylian H. Work load and demanded physical performance capacity under different industrial working conditions. In: Kaneko M, editor. Fitness for the aged, disabled, and industrial worker (International Series on Sport Sciences, 20). Champaign, IL, USA: Human Kinetics; 1990. p. 217-38. 